\title{
EFEITO DO CALCÁRIO DOLOMÍTICO E NITRATO DE POTÁSSIO NO DESENVOLVIMENTO INICIAL DE MUDAS DA BANANEIRA 'PRATA-ANÃ'(AAB), PROVENIENTES DE CULTURA IN VITRO ${ }^{1}$
}

\author{
JACKSON DE ARAÚJO DOS SANTOS², CARLOS RAMIREZ DE REZENDE E SILVA², JANICE GUEDES DE \\ CARVALHO $^{4}$, TÂNIA BRITO DO NASCIMENTO 5
}

\begin{abstract}
RESUMO - Avaliou-se o efeito do nitrato de potássio e do calcário dolomítico no desenvolvimento, em viveiro, de mudas da bananeira 'Prata-Anã', provenientes de cultura in vitro. As mudas foram plantadas em sacos de polietileno ( 32 x $14 \mathrm{~cm}$ ), contendo o substrato composto de $60 \%$ de solo, $20 \%$ de casca de arroz e $20 \%$ de areia grossa. O experimento foi desenvolvido em viveiro coberto com tela plástica (50\% de insolação), adotando-se delineamento experimental em blocos casualizados completos, com 16 tratamentos, 4 repetições e 5 plantas por parcela. Os tratamentos foram constituídos por 4 doses de calcário dolomítico ( $0 ; 3 ; 6$ e 9 kg.m³ de substrato) combinados com 4 doses de $\mathrm{KNO}_{3}(0 ; 5,1 ; 10,2$ e 20,4 g.planta.aplicação). As aplicações em cobertura, a cada 12 dias, iniciaram-se após 20 dias do transplante, com $200 \mathrm{~mL}$ de solução de $\mathrm{KNO}_{3}$ por planta. Aos 95 dias de enviveiramento, observou-se efeito apenas do $\mathrm{KNO}_{3}$, principalmente na altura das mudas, na área foliar e no número de folhas. Nas doses de $5,1 \mathrm{~g}$ e $10,2 \mathrm{~g}$ de $\mathrm{KNO}_{3}$ planta.aplicação, as mudas atingiram $18,80 \mathrm{~cm}$ e 14,71 cm de altura, respectivamente. O diâmetro do pseudocaule das mudas foi superior na dose de $5,1 \mathrm{~g}_{\text {de }} \mathrm{KNO}_{3}$. planta.aplicação, atingindo 3,44 cm. A área foliar e o número de folhas foram influenciados significativamente pelo $\mathrm{KNO}_{3}$, nas doses de 5,1 g e 10,2 g.planta.aplicação, apresentando 246,03 cm² e 10,34 e 182,14 cm² e 9,36, respectivamente. Não houve efeito do calcário para as características avaliadas.
\end{abstract}

Termo para indexação: Banana, Musa sp, cultivar Prata-Anã, viveiro, nutrientes minerais

\section{EFECT OF DOLOMIOTIC LIMESTONE AND POTASSIUM NITRATE IN THE INITIAL DEVELOPMENT OF SEEDLINGS OF 'PRATA-AN $\tilde{A}$ ' (AAB) BANANA TREE FROM IN VITRO CULTURE}

\begin{abstract}
The effect of potassium nitrate and dolomitic limestone in the initial development in nursery of 'Prata-Anã' bananas from in vitro culture was evaluated. The seedlings were planted in polyethylene bags $(32$ x $14 \mathrm{~cm})$, containing the substrate composed: of $60 \%$ of soil, $20 \%$ of rice husk and $20 \%$ of gross sand. The experiment was developed in a plastic screen-covered nursery (50\% of insolation), adopting the complete randomized block experimental design with 16 treatments, 4 replicates and 5 plants per plot. The treatments were made up of 4 doses of dolomitic limestone $\left(0,3,6\right.$ and $9 \mathrm{~kg} \cdot \mathrm{m}^{3}$ of substrate) combined with 4 doses of $\mathrm{KNO}_{3}(0,5.1,10.2$ and 20.4 g.plant.application). The topdressing applications every 12 days, started after 20 days of transplanting, performed with $200 \mathrm{~mL}$ of solution of $\mathrm{KNO}_{3}$ per plant. At 95 days of nursery, only the effect of $\mathrm{KNO}_{3}$, mainly on the height of the seedlings, on the leaf area and on the number of leaves was found. At the doses of $5.1 \mathrm{~g}$ and $10.2 \mathrm{~g}$ of $\mathrm{KNO}_{3}$. plant.application, the seedlings reached $18.80 \mathrm{~cm}$ and $14.71 \mathrm{~cm}$ in height, respectively. The diameter of the pseudo stem of the seedlings was superior at the dose of $5.1 \mathrm{~g}$ of $\mathrm{KNO}_{3}$.plant.application, reaching $3.44 \mathrm{~cm}$. Leaf areas and number of leaves were influenced significantly by $\mathrm{KNO}_{3}$ at the doses of $5.1 \mathrm{~g}$ and $10.2 \mathrm{~g} \mathrm{KNO}_{3}$.plant.application, presenting $246.03 \mathrm{~cm}^{2}$ and 10.34 and $182.14 \mathrm{~cm}^{2}$ and 9,36 , respectively. There was no effect of limestone for the evaluated characteristics.
\end{abstract}

Index Terms: Banana, Musa sp, cultivar Prata-Anã, nursery, nutrients minerals.

\section{INTRODUÇÃO}

O Brasil, considerado o segundo maior produtor mundial de bananas (FAO, 2002), vem apresentando significativo incremento desta cultura, tanto em regiões tradicionalmente produtoras como na formação de novos pólos de cultivo (Godinho, 1994). Ruggiero et al. (1994) relatam que os bananicultores têm encontrado uma série de dificuldades, a exemplo da falta de mudas em quantidade e qualidade para atender à demanda.

Na maioria dos casos, a implantação e as reformas de bananais são realizadas através de mudas procedentes de pomares velhos ou em decadência (Godinho, 1994). Essa é uma prática tecnicamente ultrapassada e desaconselhável, por contribuir para a manutenção e disseminação de plantas daninhas de difícil erradicação, além de pragas e doenças. Dessa forma, as mudas provenientes de cultivo in vitro são uma alternativa para minimizar tais problemas, já que podem ser produzidas em quantidade, qualidade e com garantia fitossanitária. Silva Neto (2001) relata a utilização de mudas de banana provenientes de micropropagação como uma prática corrente nos países que exploram a bananicultura visando à exportação. Entretanto, a utilização desse tipo de muda no Brasil é ainda restrita, mesmo com as vantagens em relação às mudas convencionais.

Segundo informações da Secretaria de Agricultura de Minas Gerais, as mudas provenientes de cultura de tecidos podem ser comercializadas com uma altura mínima de $15 \mathrm{~cm}$ (Borges, 1994). São mudas pequenas, com sistema radicular pouco desenvolvido, sensíveis às condições adversas do ambiente, tais como a falta ou excesso de água, ataque de pragas e doenças, e ocorrência de plantas daninhas na fase inicial. Por isso, há necessidade do estabelecimento de uma fase intermediária entre a saída do laboratório e o plantio definitivo no campo. $\mathrm{O}$ enviveiramento das mudas proporciona maior vigor vegetativo e desenvolvimento das raízes e rizomas, o qual influenciará decisivamente no índice de pegamento no plantio definitivo. Poucos trabalhos de pesquisa procuram estudar os detalhes desta fase intermediária entre $\mathrm{o}$ laboratório e o campo, havendo carência de informações quanto ao tipo de estrutura física do viveiro, tamanho e formas de recipientes a serem utilizados, substratos e seus componentes, práticas de manejo e, em especial, com relação ao desenvolvimento das mudas nessa etapa. A associação de conhecimentos sobre esses fatores poderá servir de subsídio para a obtenção de mudas que atendam a padrões desejáveis, em menor tempo.

O presente trabalho teve como objetivo avaliar o efeito da aplicação de diferentes doses de calcário dolomítico e $\mathrm{KNO}_{3}$ no desenvolvimento de mudas da bananeira (Musa sp) 'Prata- Anã', na fase de enviveiramento.

\footnotetext{
(Trabalho 131/2003). Recebido: 12/09/2003. Aceito para publicação: 05/03/2004.

${ }^{2}$ Eng. Agr. M.Sc. Embrapa Amazônia Ocidental - CPAA/AM, Rodovia AM - 010, Km 29, Cx. Postal 319, CEP 69011-970, Manaus-AM, jksantos@cpaa.embrapa.br, (96)241-4230

${ }^{3}$ Prof. Dr., UFLA-MG, Depart. de Agricultura, Cx. Postal 37, CEP 37.200-000, ramirez@ ufla.br, (35)3829-1122.

${ }^{4}$ Profa. Dra., UFLA-MG, Departamento de Solos, Cx. Postal 37, CEP 37.200-000, janicegc@ufla.br, (35)3829-1122.

${ }^{5}$ Estudante doutorado, INPA-AM, Cx. Postal 478, CEP 69011-970, jksantos@osite.com.br, (96)241-4230.
} 
TABELA 1 - Características físico-químicas do solo e dos substratos utilizados. UFLA, Lavra-MG, 1997.

\begin{tabular}{|c|c|c|c|c|c|c|c|c|c|c|c|c|c|}
\hline Amostra & $\begin{array}{r}\mathrm{pH} \\
\mathrm{H}_{2} \mathrm{O}\end{array}$ & $\begin{array}{c}\mathrm{P} \\
\ldots . \mathrm{n}\end{array}$ & ${ }_{3}^{\mathrm{K}}$ & $\begin{array}{c}\mathrm{Ca} \\
\ldots \ldots . .\end{array}$ & $\begin{array}{r}\mathrm{Mg} \\
\ldots \ldots .\end{array}$ & $\begin{array}{l}\mathrm{Al} \\
\mathrm{mn}\end{array}$ & $\begin{array}{c}\mathrm{H}+\mathrm{Al} \\
\mathrm{c} \cdot \mathrm{dm}^{3} \ldots .\end{array}$ & $\begin{array}{c}\mathrm{S} \\
\ldots \ldots\end{array}$ & $\begin{array}{r}\mathrm{t} \\
\ldots .\end{array}$ & $\mathrm{T}$ & \multicolumn{2}{|c|}{$\ldots . \% \ldots \ldots$} & $\begin{array}{c}\mathrm{MO} \\
\text { mg.dm }\end{array}$ \\
\hline Solo & 5,1 & 1 & 8 & 4 & 1 & 0 & 29 & 5 & 5 & 34 & 0 & 15 & 7 \\
\hline Substrato 1 & 5,7 & 64 & 64 & 14 & 2 & 1 & 29 & 18 & 19 & 47 & 5 & 38 & 7 \\
\hline Substrato 2 & 7,0 & 78 & 72 & 29 & 10 & 1 & 15 & 41 & 42 & 56 & 2 & 73 & 7 \\
\hline Substrato 3 & 7,4 & 64 & 64 & 31 & 11 & 1 & 12 & 44 & 45 & 56 & 2 & 78 & 7 \\
\hline Substrato 4 & 7,8 & 64 & 83 & 35 & 15 & 1 & 10 & 51 & 52 & 61 & 2 & 84 & 13 \\
\hline
\end{tabular}

\section{MATERIAL E MÉTODOS}

O experimento foi instalado e conduzido no viveiro do pomar da Universidade Federal de Lavras (UFLA), Minas Gerais, no período de novembro a fevereiro de 1995/96, sob estrutura coberta com tela plástica, proporcionando $50 \%$ de insolação. Foram utilizadas mudas da bananeira 'Prata-Anã', pertencentes ao grupo AAB. As mudas foram obtidas por meio da propagação in vitro, aclimatadas em bandeja de isopor, contendo como substrato vermiculita e casca de pínus compostada.

O delineamento experimental adotado foi o de blocos casualizados, com quatro repetições, esquema fatorial $4^{2}$, com quatro doses de calcário dolomítico $\left(0 ; 3 ; 6\right.$ e $9 \mathrm{~kg} . \mathrm{m}^{3}$ de substrato) e quatro doses de $\mathrm{KNO}_{3}(0 ; 5,1 ; 10,2$ e 20,4 g.planta.aplicação), num total de 16 tratamentos e 64 parcelas. Cada parcela experimental foi constituída por 5 sacos contendo uma muda.

Como recipiente, utilizou-se saco plástico preto, perfurado, com capacidade para $5 \mathrm{~L}$ de substrato e medindo $14 \mathrm{~cm}$ de diâmetro por $32 \mathrm{~cm}$ de altura. O substrato de cultivo constituiu-se de uma mistura de $60 \%$ de Latossolo Vermelho Distroférrico, 20\% de areia grossa, $20 \%$ de casca de arroz , $800 \mathrm{~g}$ de $\mathrm{P}_{2} \mathrm{O}_{5} \mathrm{~m}^{3} \mathrm{sob}$ forma de superfosfato triplo, $50 \mathrm{~g}$ de S.m ${ }^{3}$ sob a forma de enxofre em pó e calcário dolomítico, segundo os tratamentos, adicionando-se em cobertura a solução de $200 \mathrm{~mL}$ $\mathrm{KNO}_{3}$ planta.aplicação. Após um mês, realizou-se o transplante, quando as mudas apresentavam altura média de $2,70 \mathrm{~cm}$ e diâmetro de $0,55 \mathrm{~cm}$.

Decorridos 15 dias do transplante, efetuou-se uma aplicação de solução dos micronutrientes $\left(\mathrm{mg} \cdot \mathrm{dm}^{3}\right)$ : B 0,5; Cu 1,5; Mo 0,1; Zn 5,0 utilizando-se como fonte de bórax, sulfato de cobre, molibidato de amônio e sulfato de zinco, respectivamente. As aplicações do $\mathrm{KNO}_{3}$ foram feitas na forma de solução, em cobertura, após 20 dias do transplante, com intervalos regulares de 12 dias.

As variáveis de crescimento avaliadas aos 20 dias, em intervalos quinzenais até os 90 dias, foram: altura da muda, diâmetro do pseudocaule, número de folhas e área foliar. Aárea foliar foi estimada de acordo com Moreira (1987), e o diâmetro do rizoma foi medido no final do experimento.

\section{RESULTADOS E DISCUSSÃO}

O calcário dolomítico não apresentou efeito significativo (Tabela 1) para as variáveis de desenvolvimento avaliadas. Os resultados encontrados estão de acordo com os de Rodrigues (1995) para bananeira 'Mysore' na fase de enviveiramento. Saes (1995) também não encontrou correlação do calcário com as características de crescimento observadas, quando avaliou a resposta da bananeira 'Nanição' à calagem durante cinco ciclos. Pela Tabela 2, verifica-se que o calcário proporcionou alterações relevantes após 30 dias de incubação nas características químicas do substrato, como $\mathrm{pH}, \mathrm{S}, \mathrm{t}, \mathrm{v} \%, \mathrm{H}^{+}, \mathrm{Ca}^{2+}$, $\mathrm{Mg}^{2+} \mathrm{e} \mathrm{K}^{2+}$. A calagem é recomendável pra aumentar a disponibilidade de nutrientes, como N, P, K, S e Mo, fornecer $\mathrm{Ca}^{2+}$ e $\mathrm{Mg}^{2+}$, melhorar a atividade microbiana, além de ser um meio para a neutralização da acidez do solo (Martim-Prével, 1984; Carvalho et al., 1986; Borges \& Oliveira,1995).

As aplicações de $\mathrm{KNO}_{3}$ influenciaram positivamente na altura das mudas, que se apresentaram significativamente superiores nas doses de 5,1 e 10,2 g de $\mathrm{KNO}_{3}$.planta.aplicação (Tabela 2).

As mudas apresentaram ganho em altura com a elevação do $\mathrm{KNO}_{3}$ até a dose de 5,1 g.planta.aplicação (Figura 1). O mesmo não ocorreu nas doses superiores, possivelmente em decorrência da maior concentração de $\mathrm{KNO}_{3}$ no substrato, ocasionando queima nos tecidos das raízes e murcha na parte aérea, pelo aumento da pressão osmótica da solução ou, então, pelo efeito salino, como relata Malavolta (1980). O efeito depressivo do $\mathrm{KNO}_{3}$ também foi observado por Carvalho (1994), quando utilizado com maior frequiência em porta-enxertos cítricos.

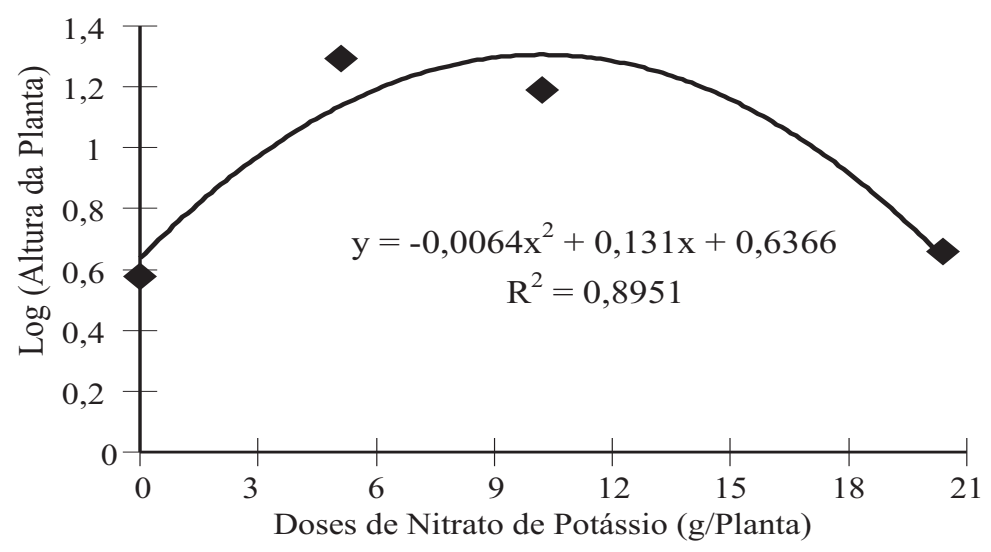

FIGURA 1 - Equação de regressão para altura média das mudas da bananeira 'Prata-Anã', em função de doses de $\mathrm{KNO}_{3}$, após 95 dias do transplante. UFLA, Lavras, MG, 1997.

TABELA 2 - Altura da planta (AP), área foliar (AF), número de folha (NF), diâmetro do pseudocaule (DP), diâmetro do rizoma (DR) de mudas da bananeira 'Prata-Anã', avaliadas aos 95 dias pós-transplante. UFLA, Lavras, MG, 1997.

\begin{tabular}{|c|c|c|c|c|c|c|}
\hline & Tratamento & $\begin{array}{l}\mathrm{AP} * \\
(\mathrm{~cm})\end{array}$ & $\begin{array}{c}\text { DP } \\
(\mathrm{cm})\end{array}$ & $\begin{array}{l}\mathrm{AF}^{*} \\
\left(\mathrm{~cm}^{2}\right)\end{array}$ & $\mathrm{NF}$ & $\begin{array}{c}\text { DR } \\
(\mathrm{cm})\end{array}$ \\
\hline $\mathrm{KNO}_{3}$ & 0 g.planta & $2,81 \mathrm{~b}$ & $0,75 \mathrm{c}$ & $16,70 \mathrm{~b}$ & $4,48 \mathrm{~b}$ & $0,00 \mathrm{~d}$ \\
\hline $\mathrm{KNO}_{3}$ & 5,1 g. planta & $18,80 \mathrm{a}$ & $3,44 \mathrm{a}$ & $246,03 \mathrm{a}$ & $10,34 \mathrm{a}$ & $4,22 \mathrm{a}$ \\
\hline $\mathrm{KNO}_{3}$ & 10,2 g. planta & $14,71 \mathrm{a}$ & $2,88 \mathrm{~b}$ & $182,14 \mathrm{a}$ & $9,36 \mathrm{a}$ & $3,56 \mathrm{~b}$ \\
\hline $\mathrm{KNO}_{3}$ & 20,4 g. planta & $4,14 \mathrm{~b}$ & $0,73 \mathrm{c}$ & $19,53 \mathrm{~b}$ & $2,48 \mathrm{c}$ & $0,40 \mathrm{c}$ \\
\hline $\mathrm{C}_{\mathrm{a}} \mathrm{Co}_{3}$ & $0 \mathrm{~kg} \cdot \mathrm{m}^{3}$ & $10,21 \mathrm{a}$ & $1,96 \mathrm{~b}$ & $126,36 \mathrm{a}$ & $6,67 \mathrm{a}$ & $2,06 \mathrm{~b}$ \\
\hline $\mathrm{C}_{\mathrm{a}} \mathrm{Co}_{3}$ & $3 \mathrm{~kg} \cdot \mathrm{m}^{3}$ & $10,06 \mathrm{a}$ & $1,99 \mathrm{~b}$ & $108,04 \mathrm{a}$ & $6,67 \mathrm{a}$ & $1,94 \mathrm{~b}$ \\
\hline $\mathrm{C}_{\mathrm{a}} \mathrm{Co}_{3}$ & $6 \mathrm{~kg} \cdot \mathrm{m}^{3}$ & $9,21 \mathrm{a}$ & $1,78 \mathrm{~b}$ & $104,27 \mathrm{a}$ & $6,48 \mathrm{a}$ & $1,99 \mathrm{~b}$ \\
\hline $\mathrm{C}_{\mathrm{a}} \mathrm{Co}_{3}$ & $9 \mathrm{~kg} \cdot \mathrm{m}^{3}$ & $10,98 \mathrm{a}$ & $2,06 \mathrm{~b}$ & $125,73 \mathrm{a}$ & $6,84 \mathrm{a}$ & $2,18 \mathrm{~b}$ \\
\hline $\mathrm{CV}(\%)$ & & 13,81 & 16,59 & 20,03 & 16,45 & 19,06 \\
\hline
\end{tabular}

* Dados transformados para $\log _{10}(x+1)$

Médias seguidas pelas mesmas letras não apresentam diferenças significativas entre si, pelo teste Tukey, a 5\% de probabilidade. 
Analisando-se o efeito da fertilização nas diferentes épocas de avaliação (Figura 2), constatou-se que houve resposta na altura das mudas ao $\mathrm{KNO}_{3}$ somente a partir do $35^{\circ}$ dia. Possivelmente, tenha ocorrido, na fase inicial, um estresse salino ou toxidez causada pelo fertilizante, bem como a possibilidade de as mudas não estarem perfeitamente adaptadas, impedindo uma absorção mais eficiente.

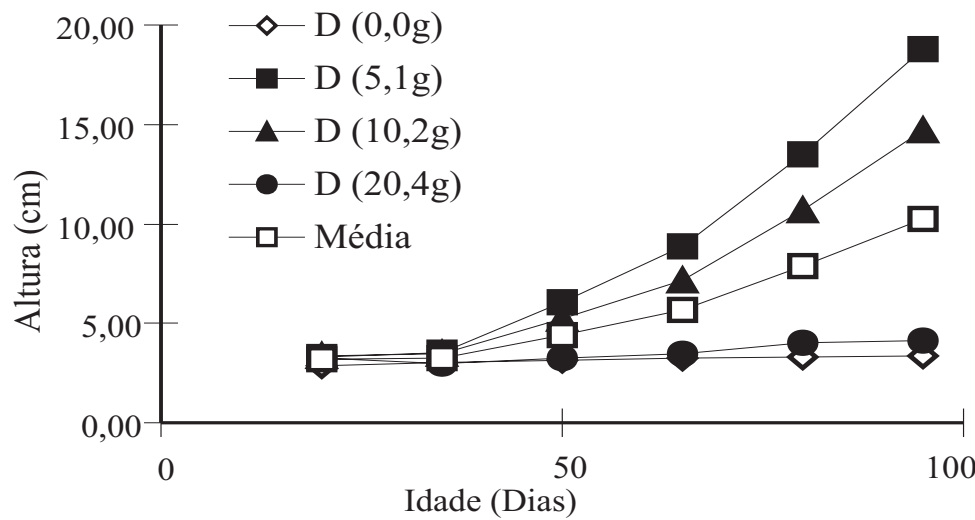

FIGURA 2 - Alturas médias das mudas da bananeira 'Prata-Anã', em função de doses de $\mathrm{KNO}_{3}$ e épocas de avaliação. UFLA, Lavras, MG, 1997.

As mudas apresentaram ganho linear em altura, em função das doses e da época de avaliação, à exceção da dose $20,4 \mathrm{~g}$ de $\mathrm{KNO}_{3}$.planta.aplicação (Figura 2), que ocasionou uma ligeira queda na fase inicial do desenvolvimento, devido à murcha das plantas e perda de folhas, possivelmente em decorrência da toxidez ou efeito salino no substrato.

Com 95 dias, a altura das mudas de 18,80 cm apresentou-se inferior àquela relatada por Vicentini (1994), de 38,98 cm aos 85 dias, com a utilização de MAP na cultivar Grand Naine, em estufa climatizada, também inferior à citada por Daniells \& Smith (1991), de 25 a $30 \mathrm{~cm}$. A variação no ganho em altura pode ser atribuída às diferentes condições de enviveiramento e ao material genético, além do aumento da pressão osmótica da solução ou efeito salino, provocado pelo fertilizante, conforme relatado por Malavolta (1980). Estudos anteriores demonstraram que a altura de plantas de bananeira foi afetada pela condutividade elétrica com nível crítico de 0,87 dS.m ${ }^{-1}$ (Israeli et al., 1986) e 1,0 dS.m ${ }^{-1}$ (Doorenbos \& Kassan, 1994).

Houve efeito significativo do $\mathrm{KNO}_{3}$ sobre o diâmetro das mudas, atingindo valor médio de $3,44 \mathrm{~cm}$ na dose de 5,1 de $\mathrm{KNO}_{3}$.planta.aplicação, significativamente superior aos demais (Tabela 2). Observa-se, através da Figura 3, que ocorreu aumento com a elevação do $\mathrm{KNO}_{3}$ até a dose de 5,1 g.planta.aplicação, a partir do qual houve redução. Kohli et al. (1984), Hernandez (1985), Hegde \& Srinivas (1989) e Vicentini (1994) correlacionaram o aumento do diâmetro do pseudocaule com adubações nitrogenadas.

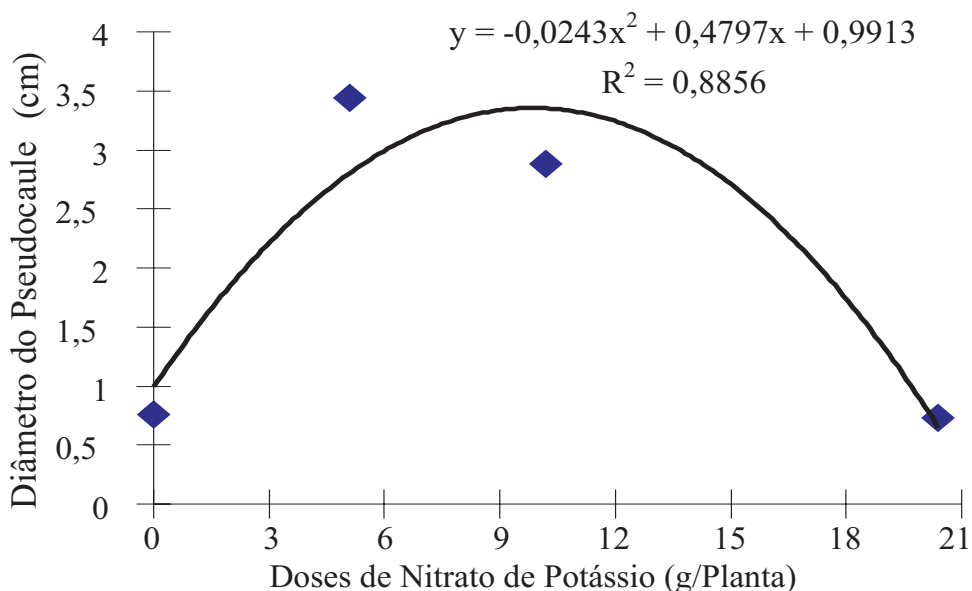

FIGURA 3 - Equação de regressão para diâmetro médio das mudas da bananeira 'Prata-Anã', em função de doses de $\mathrm{KNO}_{3}$, após 95 dias do transplante. UFLA, Lavras, MG, 1997.
Avaliando-se o efeito das doses de $\mathrm{KNO}_{3}$ nas diferentes épocas de avaliação (Figura 4), observa-se que houve resposta somente a partir dos 35 dias, conforme considerações feitas anteriormente para a variável altura. As mudas apresentaram ganho crescente em diâmetro em função das doses e épocas de avaliação.

Beugmon \& Champion (1966) verificaram que o diâmetro do pseudocaule está relacionado com o número de raízes. Simmonds (1973) afirma que o pseudocaule oferece apoio à planta e tem capacidade de armazenar reservas amiláceas e hídricas. Dessa forma, espera-se que mudas com diâmetros superiores possam originar plantas com sistema radicular mais vigoroso, favorecendo o pegamento, o crescimento e o desenvolvimento inicial, a tolerância a veranico e a ventos.

A área foliar também foi significativamente influenciada pelo $\mathrm{KNO}_{3}$ (Tabela 2), e estatisticamente superior nas doses de 5,1 e 10,2 g.planta.aplicação. A dose de 5,1 g de $\mathrm{KNO}_{3}$.planta.aplicação apresentou área foliar de $246,03 \mathrm{~cm}^{2}$, sendo $35,07 \%$ superior à área obtida na dose de $10,2 \mathrm{~g}$ de $\mathrm{KNO}_{3}$.planta.aplicação. A exemplo da altura e do diâmetro das mudas a área foliar também diminuiu nas doses acima de 5,1 g de $\mathrm{KNO}_{3}$.planta.aplicação (Figura 5).

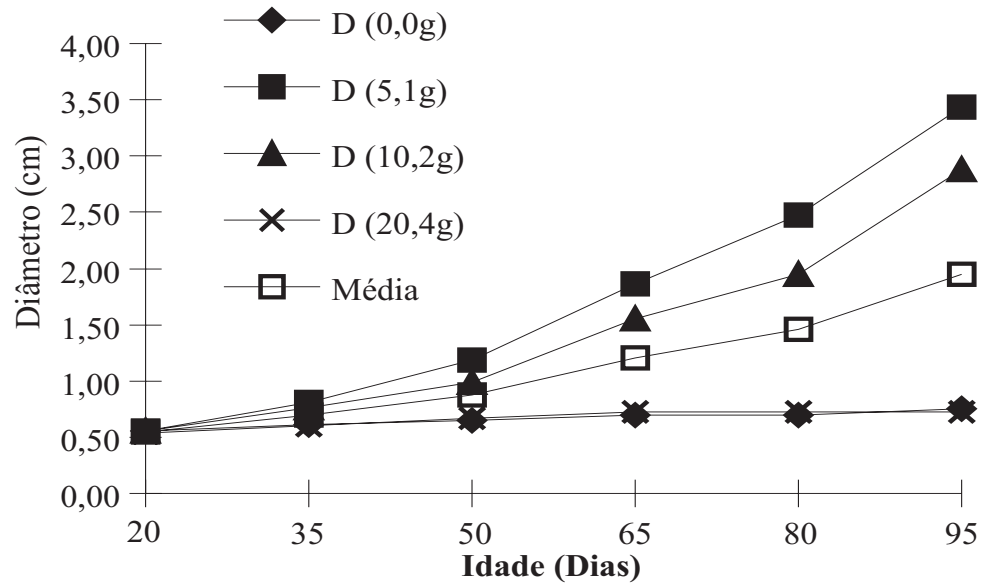

FIGURA 4 - Diâmetros médios do pseudocaule das mudas da bananeira 'Prata-“Anã', em função de doses de $\mathrm{KNO}_{3}$ e épocas de avaliação. UFLA, Lavras, MG, 1997.

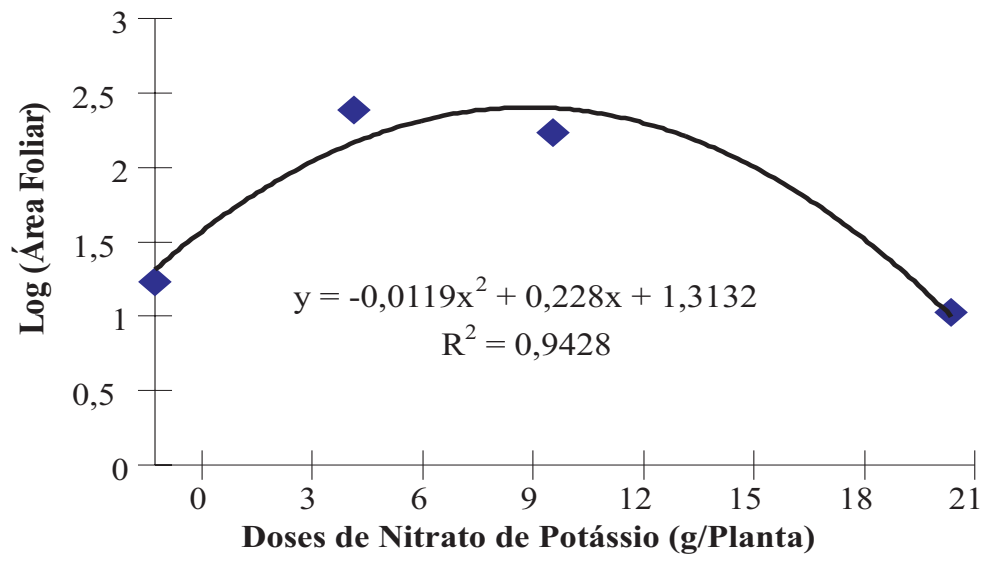

FIGURA 5 - Equação de regressão para área foliar média das mudas da bananeira 'Prata-Anã', em função de doses de $\mathrm{KNO}_{3}$, após 95 dias do transplante. UFLA, Lavras, MG, 1997.

Araújo Filho et al. (1995) observaram que condutividades elétricas de até $3,72 \mathrm{dS} . \mathrm{m}^{-1}$ não afetaram a área foliar das cultivares do grupo AAA (Nanicão e Nanica), porém afetaram as do grupo AAB (Pacovan e Mysore), havendo, inclusive, morte das folhas, semelhante ao ocorrido neste trabalho. Menguel \& Kirkby (1982) citam que a salinidade contribui para a redução do tamanho das folhas, e Vicentini (1994) relata que o aumento na salinidade, através de doses crescentes de MAP, contribuiu para a redução da área foliar.

Houve efeito significativo do $\mathrm{KNO}_{3}$ sobre o número de folhas, sendo as médias registradas nas doses de 5,1 g e 10,2 g.planta.aplicação 
significativamente superiores às demais (Tabela 2). No entanto, o número de folhas diminuiu nas doses acima de 5,1 $\mathrm{g}$ de $\mathrm{KNO}_{3}$.planta.aplicação (Figura 6).

Segundo Azeredo et al. (1986), Moreira (1987) e Medina (1993), o número de folhas é influenciado principalmente por $\mathrm{N}$ e K, e Moreira (1987) ressalta que a deficiência de N reduz a longevidade das folhas. Soto Ballestero (1992) relata que o K e o Mg são nutrientes de maior efeito na duração funcional da folha. Da mesma forma, observou-se, neste experimento, que as mudas que receberam aplicações de $\mathrm{KNO}_{3}$ apresentaram condições mais favoráveis de emissão foliar, aliadas à manutenção das mesmas por um período de tempo mais prolongado, quando comparadas com aquelas onde não houve aplicação.

Partindo-se deste princípio, mudas com maior área foliar e maior número de folhas poderão proporcionar maior índice de pegamento, acelerar o crescimento inicial e o desenvolvimento, através de maior produção de fotoassimilados, resultando, possivelmente, em maior produção.

As aplicações de $\mathrm{KNO}_{3}$ afetaram positivamente o diâmetro do rizoma, atingindo diâmetro superior na dose de 5,1 g.planta.aplicação, estatisticamente superior aos diâmetros encontrados nas outras doses testadas (Tabela 1). Pela Figura 7, verifica-se que a aplicação de $\mathrm{KNO}_{3}$ em doses acima de 5,1 g, apresentou efeito depressivo sobre esta característica.

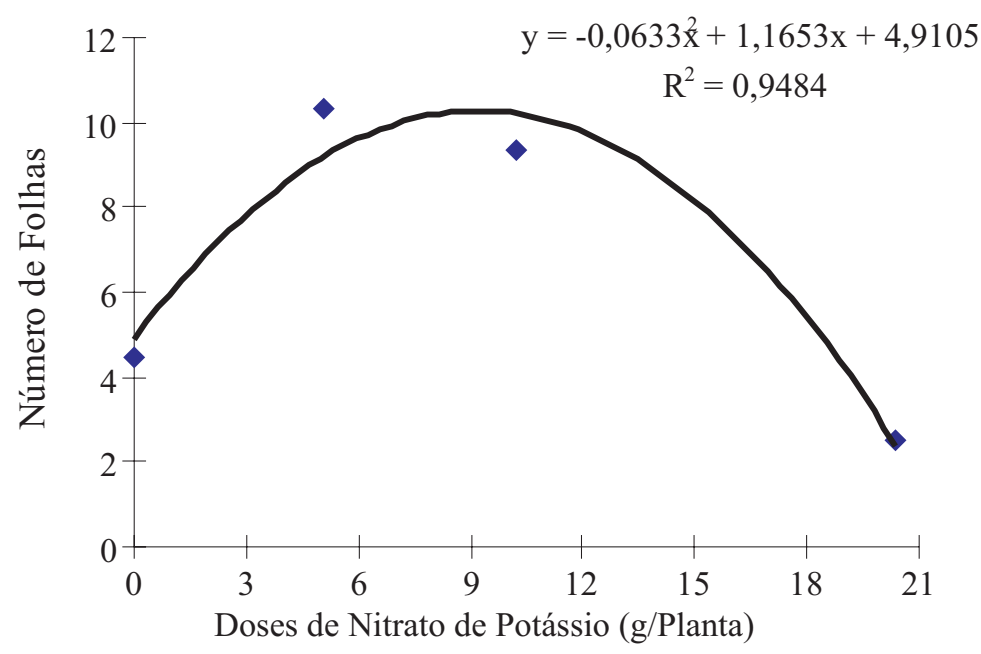

FIGURA 6 - Número médio de folhas das mudas da bananeira 'PrataAnã', em função de doses de $\mathrm{KNO}_{3}$, após 95 dias do transplante. UFLA, Lavras, MG, 1997.

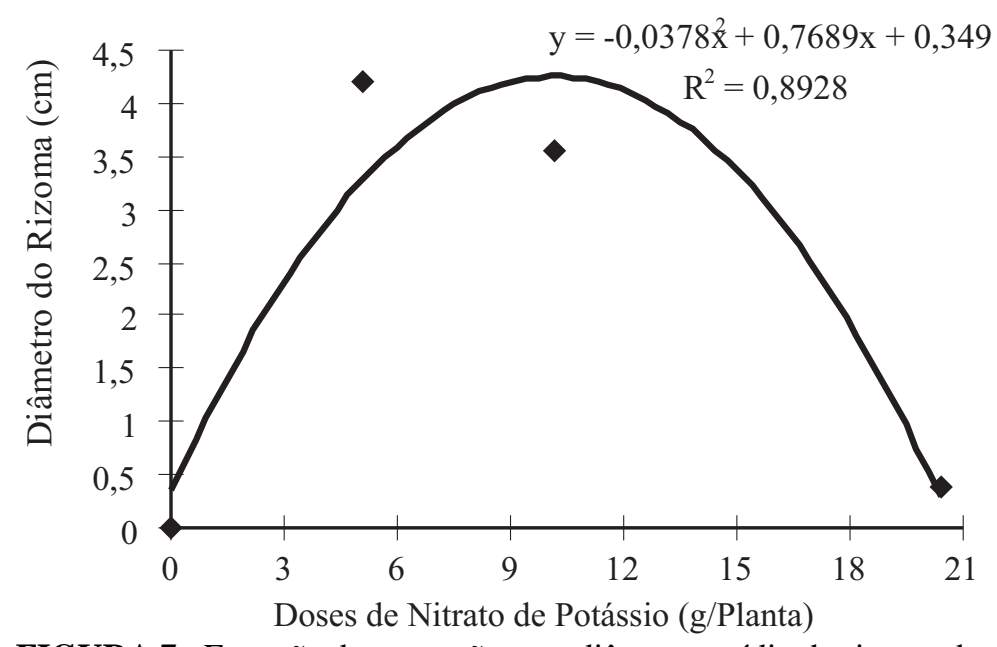

FIGURA 7 - Equação de regressão para diâmetro médio do rizoma das mudas da bananeira 'Prata-Anã', em função de doses de $\mathrm{KNO}_{3}$, após 95 dias do transplante. UFLA, Lavras, MG, 1997.
Devido à importância do rizoma como órgão de reserva (Champion, 1975; Moreira, 1987 e Soto Ballestero, 1992), mudas com diâmetro superiores, quando levadas a campo, possivelmente, terão maiores índices de pegamento, crescimento e desenvolvimento.

\section{CONCLUSÕES}

1) Doses acima de 5,1 $\mathrm{g}$ de $\mathrm{KNO}_{3}$.planta.aplicação, em intervalos de 12 dias, promoveram efeito depressivo nas mudas da bananeira 'PrataAnã' para todas as características de crescimento avaliadas.

2) A dose de $5,1 \mathrm{~g}$ de $\mathrm{KNO}_{3}$ planta.aplicação proporcionou mudas da bananeira com características de crescimento significativamente superiores àquelas em que essa fonte não esteve presente.

3) Não houve efeito do calcário dolomítico, nas doses avaliadas, para as características de crescimento de plantas.

\section{REFERÊNCIAS BIBLIOGRÁFICAS}

ALMEIDA, V.F. de. Nematóides em fruteiras. Informe Agropecuário, Belo Horizonte, v.16, n.172, p.65-72, 1992.

ARAÚJO FILHO, J.B. de; GHEYI, H.R.; AZEVEDO, N.C. de. Tolerância da bananeira à salinidade em fase inicial de desenvolvimento. Pesquisa Agropecuária Brasileira, Brasília v.30, n.7, p.989-997, jul. 1995.

AZEREDO, J.A. de; GENÚ, P.Y.C. de; AQUINO, A.R.L. de; CAMPELO JÚNIOR, J.H.; RODRIGUEZ, A.P.M. Nutrição mineral e adubação da bananeira. In: HAAG, H.P. (Coord.) Nutrição mineral e adubação de frutíferas tropicais do Brasil. Campinas: Fundação Cargill, 1986. p.59-102.

BORGES, A. L.; OLIVEIRA, A. M. G. Nutrição e adubação de bananeira. In: MINISTÉRIO DAAGRICULTURA, DO ABASTECIMENTOE DAREFORMAAGRÁRIA SECRETARIADEDESENVOLVIMENTO RURAL-SDR. Banana para exportação: aspectos técnicos da produção. Brasília: EMBRAPA-SPI, 1995. p.25-35 (Série publicações técnicas FRUPEX, 18).

BEUGNON, M.; CHAMPION, J. Étude sur racines du bananier. Fruits, Paris, v.21, n.7, p. 309-327, 1966.

CARVALHO, S.A. de. Manejo da adubação nitrogenada na produção de porta-enxertos cítricos em bandejas. 1994. 74f. Tese (Doutorado em Fitotecnia) - Universidade Federal de Lavras, Lavras, 1994.

CHAMPION, J. El platano. Barcelona: Editorial Blume, 1975. 247p.

DANIELS, J.; SMITH, M. Post-flask management of tissue cultured bananas. Camberra: ACIAR, 1991. 8p. (Technical Reports, 18).

DOORENBOS , J; KASSAM, A.H. Efeito de água no rendimento das culturas. Campina Grande : UFPB, 1994. 306p. (Estudos FAO. Irrigação e Drenagem)

FAO Statistical database. Disponível em: <http: //www.fao.org.> Acesso: em 28 abril de 2002.

GODINHO, E.P de. Mudas de bananeira: tecnologia de produção. Belo Horizonte: EPAMIG, 1994. 44p. (Boletim Técnico, 4).

HEGDE, D.M.; SRINIVAS, K. Effect of soil matric potential and water use of banana. Agricultural Water Magnegement, Amsterdam, v.16, p.109-117, 1989.

HERNANDEZ, T. Influencia de los niveles de nitrogeno en el cultivo del platano vianda Musa sp. variedade "Hembra 3/4". Ciencia e Tecnologia en la Agricultura; suelos e agroqímicca, Havana, v.8, n.1, p.7-17, feb. 1985.

ISRAELI, Y.; Lahav, E.;NAMERI, N. The effect of salinity and sodium adsorption ratio of wate, on growth and productivity of bananas under drip irrigation conditions. Fruits, Paris, v.41, p.297-302, 1986. KOHLI, R.R.; IYENGAR, B.R.V.; REDDY, Y.T.N. Growth, dry matter 
production and yeld in Robusta banana as influenced by different levels of nitrogen. Indian Journal of Horticulture, Bangalore, v.41, n.3/4, p.194-198, 1984.

MALAVOLTA, E. Elementos de nutrição mineral de plantas. Piracicaba: Ceres, 1980. 215p.

MEDINA, J.C. Cultura. In: MEDINA, J.C.; BLEINROTH, E.W.; MARTININ, Z.J. de et al. Banana: cultura, matéria-prima, processamento e aspectos econômicos. 2. ed. Rev. e Ampl. Campinas: ITAL, 1993. Cap. 1 ,P.1-131. (Série Frutos Tropicais, 3).

MENGUEL, K.; KIRKBY, E. A. Principles of plant nutrition. 3. ed. ver. Switzerland: Internacional Potash Institute, 1982.655p.

MOREIRA, R.S. Banana: teoria e prática de cultivo. Campinas: Fundação Cargill, 1987.335p.

RUGGIERO, C.; GOTARDI, M.V.C. ; NOGUEIRAFILHO, GC. Propagação da bananeira In: CICLO DE PALESTRAS SOBREACULTURADA
BANANEIRA, Campinas, 1994. Anais... Campinas: Instituto Biológico, 1994. p.23-28.

SAES, L.A. Resposta da bananeira 'Nanicão' 'a calagem na região do vale do Ribeira. Piracicaba: ESALQ, 1995. 82p. (Mestrado em Fitotecnia)

SILVANETO, S.P. da. Propagação por biotecnologia. In: RUGGIERO, C. (Coord.) SIMPÓSIO BRASILEIRODE BANANICULTURA, 4., 1994. Campinas. Anais... Jaboticabal: FUNEP, 2001. p.128-149.

SIMMONDS, N.W. Los platanos. Barcelona: Editorial Blume, 1973.539p. SOTO BALLESTERO, M. Bananas: Cultivo y comercializacion. 2. ed. San José: Litografia e Imprenta LIL, 1992. 649p.

VICENTINI, S. Efeito de doses e intervalos de aplicação de MAP no crescimento de mudas de bananeira cv. Grand Naine obtidas "in vitro”. 1994. 99f. Dissertação (Mestrado em Fitotecnia). Universidade Federal de Lavras, Lavras, 1994. 